\title{
Neutrophil leukotriene generation increases after cardiopulmonary bypass
}

\begin{abstract}
Background: Leukotriene $B_{4}$ has been shown to play a role in the systemic inflammatory response after cardiopulmonary bypass in experimental animal models; however, the importance of this mediator in human beings undergoing cardiac operations has not been established. Methods: The neutrophils of ten patients undergoing coronary artery bypass grafting with cardiopulmonary bypass were studied for their ability to generate leukotrienes at the time of the induction of anesthesia, the institution of cardiopulmonary bypass, the removal of the aortic crossclamp, at the end of the operation, on admission to the intensive care unit, and on postoperative days 1 and 2. Results: After cardiopulmonary bypass, the generation of chemotactic leukotrienes rose significantly and remained elevated on the first postoperative day compared with prebypass values (prebypass $133.8 \pm 10.7$ versus postbypass $192.7 \pm 19.2[p<0.05]$ and first postoperative day $196.6 \pm 13.8[p<0.05])$. The increases in plasma complement and lactoferrin levels, although significant, were not sustained. In addition to the neutrophil count, the potential leukotriene and oxygen radical produced was significantly increased, and this increase was correlated with postoperative length of stay. Conclusion: These observations support the laboratory data documenting that the rise in leukotriene generation after cardiopulmonary bypass includes human patients. (J ThORAC CARDIOvasc SuRg 1994;108:642-7)
\end{abstract}

Dominick Gadaleta, MD, ${ }^{*}$ A. Leilani Fahey, MD, ${ }^{*}$ Madhu Verma, MS, Wilson Ko, MD, Karl H. Kreiger, MD, O. Wayne Isom, MD, and John Mihran Davis, MD, New York, N.Y.

Th he inflammatory response seen after operations requiring cardiopulmonary bypass has been well studied in inanimate and animal models, as well as in human patients. Although the importance of the neutrophil in pulmonary, renal, and cardiovascular injuries induced by cardiopulmonary bypass has been substantiated, ${ }^{1-12}$ the cytokines/mediators triggering this event in human beings have not been identified. Initial studies explored the possibilities that the prostanoids, complement- or neutrophil-derived granules, were the primary mediators in this event. ${ }^{2-11,13-15}$ Recently, in an animal model of cardiopulmonary bypass, inhibition of leukotrienes during cardioplegic arrest and before reperfusion prevented

From Cornell University Medical Center, New York, N.Y.

Received for publication Nov. 12, 1993.

Accepted for publication Mar. 16, 1994.

Address for reprints: John Mihran Davis, MD, Department of Surgery, Cornell University Medical Center, 1300 York Ave., New York, NY 10021.

*Present address: North Shore University Hospital, 300 Community Dr., Manhasset, NY 10030

Copyright ${ }^{(C)} 1994$ by Mosby-Year Book, Inc.

0022-5223/94 \$3.00+0 $\quad \mathbf{1 2 / 1 / 5 6 2 5 4}$ myocardial stunning and eliminated ventricular arrhythmias. ${ }^{16}$ This study suggests that $\mathrm{LTB}_{4}$ may have a primary role in precipitating the cardiac insufficiency seen after extracorporeal circulation. Furthermore, the overall well-being of the patients may be related to the inflammatory response after cardiopulmonary bypass, because patients receiving steroids are known to do better. ${ }^{17,18}$

The following study was performed to determine whether neutrophil-mediated production of leukotrienes increases in human beings during elective coronary bypass and to investigate the clinical significance of such an occurrence.

\section{Methods}

Patients. Ten consecutive patients undergoing elective coronary bypass grafting (by K.H.K. or O.W.I.) at The New York Hospital-Cornell Medical Center were prospectively studied. All procedures were performed with the patient under general endotracheal anesthesia and monitored with a Swan-Ganz catheter (Baxter Healthcare Corp., Edwards Div., Irvine, Calif.). All patients received only prophylactic antibiotics, cefazolin $1 \mathrm{gm}$ intravenously or vancomycin $500 \mathrm{mg}$ intravenously before skin incision and for 24 hours after the operation. Patients requiring antibiotic therapy within 7 days of the operation for established infection were excluded from the study. 


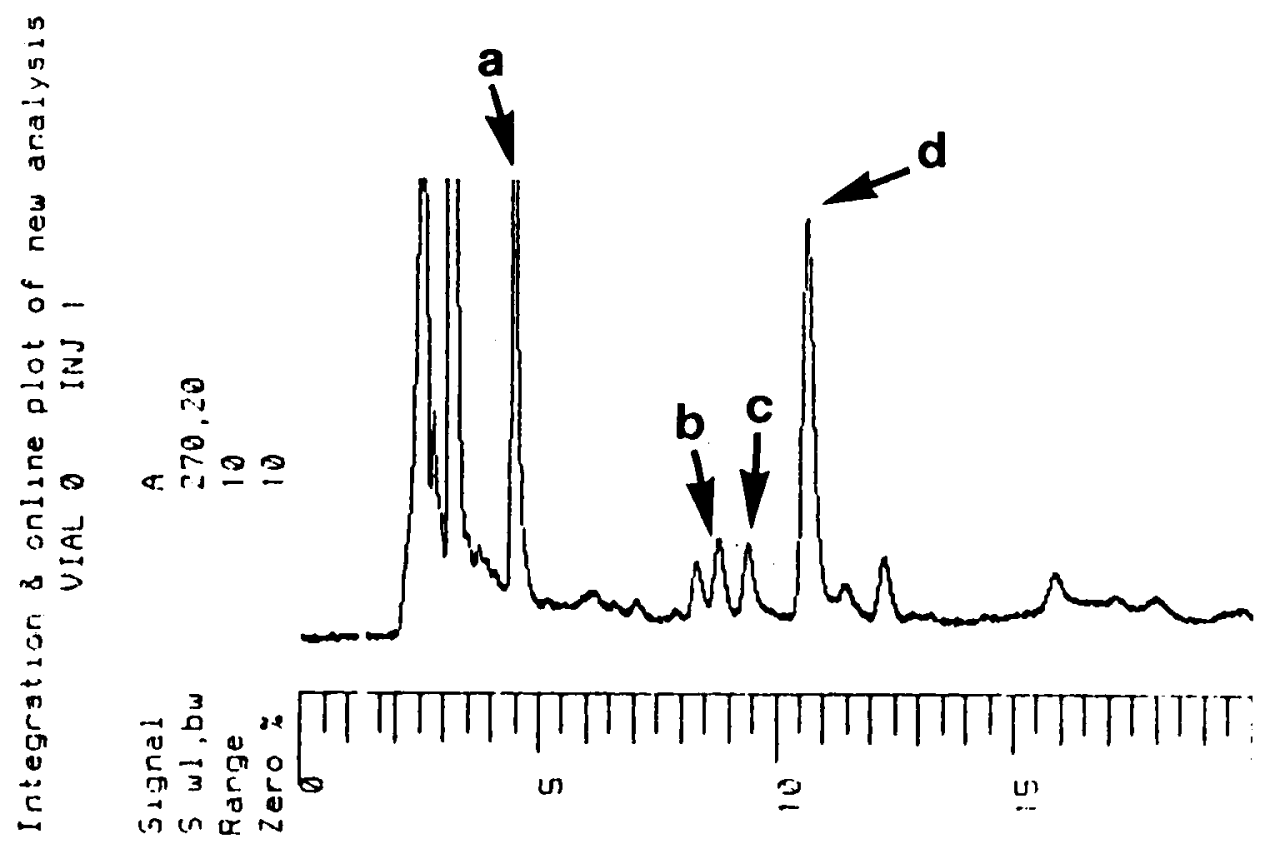

Fig. 1. Representative chromatograph showing the chemotactic leukotrienes: $\mathbf{a}, 20-\mathrm{OH} \mathrm{LTB}$; $\mathbf{b},(5 \mathrm{~S}, 12 \mathrm{R})$-dihydroxy eicosatetraenoic acid; $c,(5 S, 12 S)$-dihydroxy eicosatetraenoic acid; $\mathbf{d}$, the $\mathrm{LTB}_{4}$ peak.

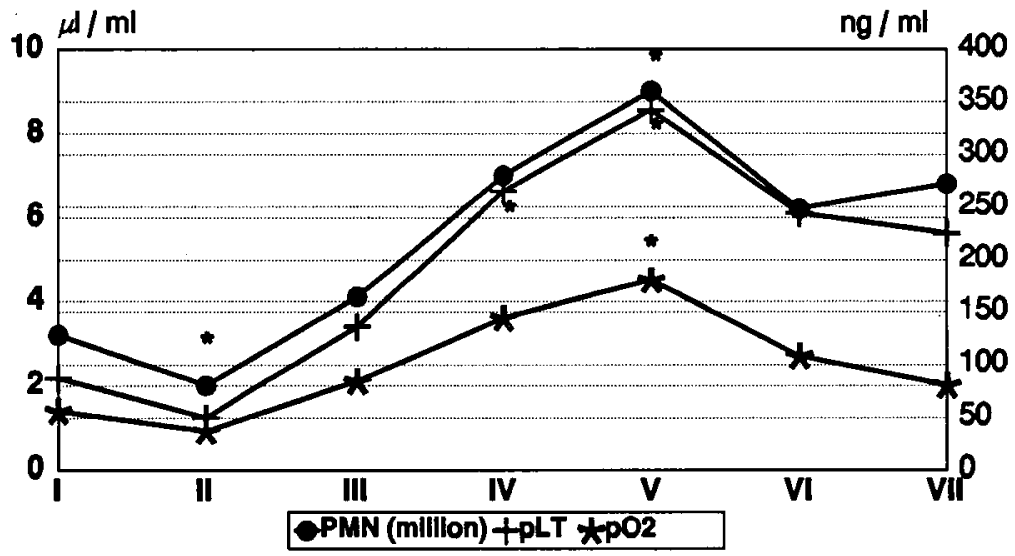

Fig. 2. Neutrophil counts (solid circles, y axis on left), potential leukotrienes $(p L T)$ generated per milliliter of blood (crosses, y axis on right), and potential oxygen $\left(\mathrm{pO}_{2}\right)$ consumption per millileter of blood (asterisks, y axis on left) during the seven time points that blood was collected. ${ }^{*} p<0.05$ versus data point $I$.

Each patient received heparin $3 \mathrm{mg} / \mathrm{kg}$ intravenously just before establishment of cardiopulmonary bypass. Intraoperative fluid management including transfusion of autologous blood and blood retrieved from the Cell Saver System (Haemonetics Corp., Natick, Mass.) was determined by the attending anesthesiologist. All blood was transfused through a $40 \mu \mathrm{m}$ filter. Patients routinely received a mixture of crystalloid (Normosol) and colloid ( $25 \%$ albumin) as part of the pump solution. Decisions related to postoperative management of fluids and ventilators were made by cardiothoracic fellows (postgraduate year 6 or more), who were unaware of the nature of the study and the accumulating data. Intraoperative cardiac events were excluded by serial electrocardiograms, cardiac isoenzyme determination, and rhythm monitoring after the operation. All patients were monitored in an intensive care unit until extubation and mobilization of fluids. This study was done with the approval of an institutional review board protocol.

Blood drawing protocol. A total of $21 \mathrm{ml}$ of blood was drawn from the radial artery into heparinized tubes at seven time points: (I) after induction of general anesthesia, (II) 5 minutes after initiation of cardiopulmonary bypass, (III) 5 minutes after removal of the aortic crossclamp, (IV) 30 minutes after restitu- 
Table I. Patient demographics and clinical parameters

\begin{tabular}{lc} 
& Mean $\pm S D$ \\
\hline No. & 10 \\
Age (yr) & $66.6 \pm 12.2$ \\
Preop. ejection fraction (\%) & $42.5 \pm 6.8$ \\
No. of grafts & $3.3 \pm 1.2$ \\
CPB time (min) & $88.4 \pm 21.1$ \\
Crossclamp time (min) & $42.9 \pm 12.9$ \\
Anesthesia time (min) & $310.5 \pm 51.0$ \\
ICU stay (days) (range 1-8 days) & $2.1 \pm 2.1$ \\
Duration of intubation (days) & $1.3 \pm 0.48$ \\
Postop. length of stay (days) & $10.6 \pm 4.1$ \\
$\quad$ (range 7-2l days) & \\
Transfusions in OR (U) (range & $0.7 \pm 1.64$ \\
$\quad$ 0-5 U) & \\
Transfusions postop (0-7) (range & $1.7 \pm 2.4$ \\
$\quad$ 0-7 U) & \\
Pressors used (all <36 hr) & $60 \%$ \\
Postop. fluid gradient (L) & $4.15 \pm 0.91$ \\
\hline
\end{tabular}

$S D$, Standard deviation; $C P B$, cardiopulmonary bypass; $I C U$, intensive care unit; $O R$, operating room.

tion of normal blood flow, (V) on admission to the intensive care unit, (VI and VII) on the morning of postoperative days 1 and 2.

A $50 \mu \mathrm{l}$ sample of blood was removed for the determination of neutrophil counts by means of a Coulter Counter (Coulter Electronics, Inc., Hialeah, Fla.) and smear. The remaining blood was immediately centrifuged, and the plasma was reserved for determination of C3a (Radioimmunoassay, Amersham Corp., Arlington Heights, Ill.) and lactoferrin (enzymelinked immunosorbent assay with rabbit antihuman antibody).

Neutrophils were isolated from the red cell pellet by standard methods of sodium diatrizoate-sucrose polymer (HypaqueFicoll) discontinuous gradient and dextran sedimentation. ${ }^{19}$ Residual red blood cells were lysed with hypertonic saline solution. The purified neutrophils were resuspended in buffered saline at standard concentrations for assay. For neutrophil generation of leukotrienes, cells were resuspended at a concentration of $5 \times 10^{6}$ cells per milliliter. For neutrophil oxygen consumption assays, cells were resuspended at a concentration of $7.5 \times 10^{6}$ cells per $3 \mathrm{ml}$. Final preparations were uniformly greater than $98 \%$ neutrophils, and trypan blue exclusion consistently revealed greater than $99 \%$ viability.

Neutrophil generation of leukotrienes. Production of leukotrienes by neutrophils was studied by means of a modification of the method of Borgeat and Samuelsson. ${ }^{20}$ Neutrophils were resuspended in phosphate-buffered saline with added calcium chloride $(2 \mu \mathrm{l})$ and magnesium chloride $(0.5 \mathrm{ml})$ to a final concentration of 5 million neutrophils per milliliter. After a 5-minute incubation at $37^{\circ} \mathrm{C}$, a $1 \mu \mathrm{l}$ concentration of calcium ionophore A23187 was added. After a second 5-minute incubation at $37^{\circ} \mathrm{C}$, the neutrophil suspensions were placed on ice to stop the reaction. The suspension was then centrifuged at $1400 \mathrm{~g}$. The supernatant lipids were extracted into ethyl acetate. Leukotriene production was quantitated by reversed-phase highpressure liquid chromatography with $75 \%$ methanol and $25 \%$ water solvent, $\mathrm{pH} 5.4$, to which $0.02 \%$ acetic acid was added. This solvent system allowed for the wide separation of $\mathbf{L T B}_{4}$ and its by-product, 20-OH $\mathrm{LTB}_{4}$. Elution of leukotrienes was determined by an ultraviolet photometer at $270 \mu \mathrm{m}$. Results were standardized by comparison with known amounts of each compound. The data are expressed either as the potential leukotriene per milliliter of blood or simply, leukotrienes. Leukotrienes are the sum of the chemotactic leukotrienes generated from 5 million neutrophils. Potential leukotrienes are the sum of the chemotactic leukotrienes generated from 5 million neutrophils, multiplied by the peripheral blood neutrophil count at the time the blood was drawn. A representative chromatograph is shown in Fig. 1.

Oxygen consumption. A $3 \mathrm{ml}$ sample of a suspension of $7.5 \times 10^{6}$ neutrophils per $3 \mathrm{ml}$ in a buffered saline solution was added to chambers containing a Clark oxygen electrode (Yellow Springs Instrument Co., Yellow Springs, Ohio). A stimulus was added (phorbolmyristate acetate $0.1 \mu \mathrm{g} / \mathrm{ml}$ ) and, after equilibration, oxygen consumption in 5 minutes was determined polarographically. This is a standard assay to assess the oxygen burst of the neutrophil and is directly correlated with oxygen radical production. ${ }^{21}$ The data are quantitated as the amount of oxygen consumed per 5 minutes per 7.5 million cells. The data are expressed as either oxygen consumption in 5 minutes per 7.5 million neutrophils or the potential amount of oxygen consumed per milliliter of blood, which is the amount consumed by 7.5 million neutrophils, multiplied by the peripheral blood neutrophil count at the time the blood was drawn.

Clinical data. The ratio of arterial oxygen consumption to inspired oxygen fraction was calculated from the first arterial blood gas drawn after admission to the intensive care unit. The fluid gradient was calculated as total intake less output for the first 24 hours after admission to the intensive care unit.

All data are expressed as mean plus or minus standard deviation of the mean, and a $p$ value less than 0.05 indicated statistical significance. Statistical significance was determined by means of analysis of variance with Neuman-Keuls multiple range test for all sequential data.

\section{Results}

Ten patients, eight male and two female $(66.6 \pm 12.2$ years), underwent successful coronary artery bypass grafting with cardiopulmonary bypass. Table I lists the clinical data for all ten patients. All patients were treated on a nonemergency basis with good left ventricular function (preoperative ejection fraction $42.5 \% \pm 6.8 \%$, average number of grafts $3.3 \pm 1.2$ ). At least one mammary artery was used in six patients. All operations were performed by cardiothoracic fellows and supervised by an attending cardiothoracic surgeon. Hemodynamics and pulmonary function were carefully monitored and optimized through the seven data collection points. All patients were discharged alive from the hospital. The discharge day ranged from day 7 to day 21 after the operation (mean $10.6 \pm 4.0$ days, median 9 days).

No intraoperative or postoperative cardiac complications were identified. Seven patients were discharged before postoperative day 10 . One patient was discharged on day 10 , one patient was discharged on day 14 , and one patient had a large left pleural effusion on postoperative 


\begin{tabular}{lccccccc}
\hline & \multicolumn{7}{c}{ Time points } \\
\cline { 2 - 8 } & \multicolumn{1}{c}{$I$} & $I I$ & $I I I$ & $I V$ & $V$ & $V I$ & $V I I$ \\
\hline PMN $\left(\times 10^{6}\right)$ & $3.2 \pm 0.9$ & $2.0 \pm 0.6 \ddagger$ & $4.1 \pm 1.7$ & $7.0 \pm 3.0$ & $9.0 \pm 5.9^{*}$ & $6.0 \pm 2.9$ & $6.8 \pm 3.4$ \\
LT $\left(\mathrm{ng} / 5 \times 10^{6} \mathrm{PMN}\right)$ & $134 \pm 30$ & $134 \pm 42$ & $173 \pm 70$ & $193 \pm 54^{*}$ & $176 \pm 32$ & $197 \pm 39^{*}$ & $175 \pm 59$ \\
$\mathrm{O}_{2}\left(\mu \mathrm{l} / 5 \mathrm{~min} / 7.5 \times 10^{6} \mathrm{PMN}\right)$ & $3.2 \pm 0.62$ & $3.5 \pm 0.87$ & $3.9 \pm 0.71 \S$ & $3.9 \pm 1.4 \S$ & $3.8 \pm 0.35 \S$ & $3.3 \pm 1.6$ & $2.2 \pm 0.64$ \\
$\mathrm{LF}(\mathrm{ng} / \mathrm{ml})$ & $0.32 \pm 0.29$ & $0.51 \pm 0.26$ & $1.45 \pm 0.82 \ddagger$ & $0.53 \pm 0.58$ & $0.37 \pm 0.28$ & $0.26 \pm 0.19$ & $0.26 \pm 0.16$ \\
$\mathrm{C} 3 \mathrm{a}(\mu \mathrm{g} / \mathrm{ml})$ & $0.34 \pm 0.24$ & $0.68 \pm 0.53$ & $1.27 \pm 0.52 \dagger$ & $1.54 \pm 0.52 \dagger$ & $1.33 \pm 0.77 \dagger$ & $0.31 \pm 0.22$ & $0.49 \pm 0.39$ \\
\hline
\end{tabular}

$I$, After induction of general anesthesia; $I I$, after initiation of cardiopulmonary bypass; $I I I, 5$ minutes after aortic clamp removal; $I V$, 30 minutes after restitution of normal blood flow; $V$, on admission to the intensive care unit; $V I$, postoperative day 1 ; $V I I$, postoperative day 2 . PMN, Polymorphonuclear leukocytes (neutrophils); $O_{2}$, oxygen; $L F$, lactoferrin.

$* p \leq 0.05$ versus $\mathrm{I}$.

$t p \leq 0.001$ versus I.

$\ddagger p \leq 0.05$ versus IV, V, VI and VII

$\S p \leq 0.05$ versus VII

Table III. Potential leukotriene $(p L T)$ and oxygen radical $\left(\mathrm{PO}_{2}\right)$ generation

\begin{tabular}{lccccccc}
\hline & \multicolumn{7}{c}{ Time points } \\
\cline { 2 - 7 } & $I$ & $I I$ & $I I I$ & $I V$ & $V$ & VI & VII \\
\hline $\mathrm{PMN}\left(\times 10^{6} \mathrm{PMN} / \mathrm{ml}\right)$ & $3.2 \pm 0.9$ & $2.0 \pm 0.6 \neq$ & $4.1 \pm 1.7$ & $7.0 \pm 3.0$ & $9.0 \pm 5.9^{*}$ & $6.0 \pm 2.9$ & $6.8 \pm 3.4$ \\
$\mathrm{pLT}(\mathrm{ng} / \mathrm{ml})$ & $87 \pm 35$ & $50 \pm 21$ & $136 \pm 85$ & $265 \pm 148^{*}$ & $342 \pm 219 \dagger$ & $244 \pm 138$ & $225 \pm 90$ \\
$\mathrm{pO}_{2}(\mu \mathrm{l} / \mathrm{ml})$ & $1.4 \pm 0.3$ & $0.92 \pm 0.2$ & $2.1 \pm 0.4$ & $3.6 \pm 1.3$ & $4.5 \pm 0.4^{*}$ & $2.7 \pm 1.4$ & $2.0 \pm 0.6$ \\
\hline
\end{tabular}

$I$, After induction of general anesthesia; $I I$, after initiation of cardiopulmonary bypass; $I I I, 5$ minutes after aortic clamp removal; $I V, 30$ minutes after restitution of normal blood flow; $V$, on admission to the intensive care unit; $V I$, postoperative day 1 ; $V I I$, postoperative day 2 .

${ }^{*} p \leq 0.05$ versis $\mathrm{I}$.

$\dagger p \leq 0.001$ versus I.

$\ddagger p \leq 0.05$ versus IV, V, VI, and VII.

day 2 and required endotracheal reintubation and tube thoracostomy. She was discharged on postoperative day 21.

Table II lists the neutrophil data from all 10 patients at the seven time points that blood was collected. The neutrophil counts more than doubled by the end of the procedure, and lactoferrin levels significantly increased after removal of the aortic crossclamp. Complement levels also significantly increased after removal of the aortic clamp, but unlike lactoferrin, the increase was sustained, lasting through admission to the intensive care unit and returning to baseline on postoperative day 1 .

Polarographically measured neutrophil oxygen consumption, a measure of oxygen radical formation, was significantly increased after removal of the aortic clamp and paralleled the increase in complement. Finally, neutrophil leukotriene generation significantly increased 30 minutes after cessation of cardiopulmonary bypass (data collection point IV) and remained elevated on postoperative day 1 .

Table III (Fig. 2) lists potential neutrophil leukotriene generation and potential neutrophil oxygen radical formation. This is a derived number obtained by multiplying the patient's neutrophil count by the amount of leu- kotriene generated and oxygen consumed per cell. These data were calculated to compare the potential amounts of $\mathrm{LTB}_{4}$ made in $1 \mathrm{ml}$ of blood from different patients. Individual neutrophils may make decreased amounts of oxygen-derived radicals and cytokines at times of stress, but because of the rise the neutrophil count, the potential amount of cytokine released per milliliter of blood is increased over that of normal control subjects. 22

Analysis of these data on admission to the intensive care unit (data point $\mathrm{V}$ ) closely correlates with postoperative length of stay (neutrophils: $r=0.88, p<0.001$; potential leukotriene generation: $r=0.83, p<0.01$; potential neutrophil oxygen radical formation: $r=0.75$, $p<0.01)$. Clinical data that are thought to be relevant to postoperative length of stay were then analyzed to determine the relationship each had with postoperative length of stay. As expected, preoperative ejection fraction, degree of coronary disease (as measured by intraoperative transfusion requirement and bypass time), and postoperative cardiac output all significantly correlated with postoperative length of stay $(p<0.05)$. In addition, neutrophil count, potential leukotriene generated neutrophils, and potential oxygen radical formation also positively correlated with length of stay. Analysis of these data with 
respect to clinical factors thought to represent "postpump" phenomenon (fluid requirement, ratio of arterial oxygen tension to inspired oxygen fraction) did not elucidate the mechanism behind the associations described herein.

\section{Discussion}

Cardiac operations with cardiopulmonary bypass and extracorporeal circulation are known to cause activation of the complement, kallikrein, bradykinin, and coagulation cascades, as well as activation of platelets and release of neutrophil granular components. ${ }^{1-15}$ Additionally, recent evidence has shown a detectable increase in the proinflammatory mediators, specifically, tumor necrosis factor- $\alpha$, interleukin-1, interleukin-6, and possibly bacterium-derived lipopolysaccharides. ${ }^{1}$ Taken in combination, these biologic events do not explain all of the hemodynamic, pulmonary, or cardiac manifestations occurring after cardiopulmonary bypass.

Leukotrienes are produced when arachidonic acid is released from the neutrophil membrane and metabolized by lipoxygenase. ${ }^{23}$ The leukotrienes, specifically $\mathrm{LTB}_{4}$, its metabolites, and stereoisomers, are potent chemotactic and aggregating agents that also mediate vascular permeability and blood flow. The leukotrienes are known to contribute, at least in part, to pulmonary and renal dysfunction after shock caused by trauma, burns, and sepsis. ${ }^{24}$ Increased tissue levels of $\mathrm{LTB}_{4}$ are found after ischemia/reperfusion, and an increase in the potential ability of the neutrophil to produce leukotrienes has been noted to precede and predict the occurrence of pulmonary and renal dysfunction after severe septic or traumatic challenge. ${ }^{25,26}$ These studies have shown a temporal relationship between biologic phenomenon (mediator changes) and subsequent clinical outcome. Our study confirms earlier observations that neutrophil and complement activation occur during cardiopulmonary bypass. The release of lactoferrin, a neutrophil-specific granule component, and the rise in $\mathrm{C} 3 \mathrm{a}$ levels are pronounced. Levels of each are several times baseline and are shortlived, possibly because the parameters being assayed are derived from products of the activation of preformed proteins.

This study is the first to show an increase in the ability of neutrophils to produce oxygen radicals after cardiopulmonary bypass. With the use of a Clark oxygen electrode, neutrophil consumption of oxygen was measured by changes in the oxygen tension of oxygen-rich media. Because oxygen consumption by neutrophils leads directly to oxygen radical formation, this is a reliable measure of the ability of neutrophils to produce oxygen radicals. ${ }^{27}$ Because the graphs describing oxygen consumption and complement activation closely parallel each other, we believe this represents a true relationship. Further investigation of oxygen radical formation and complement activation is ongoing.

This study shows a strong relationship between neutrophil count, neutrophil cytokine release, and outcome after cardiopulmonary bypass. Although others have implicated prostanoids in the cardiopulmonary dysfunction seen after cardiac operations, no one has shown that the production of $\mathrm{LTB}_{4}$ and its isomers is directly related to outcome. Our data suggest that such a relationship may exist.

As expected, preoperative left ventricular ejection fraction, number of bypass grafts, and postoperative cardiac output can also be correlated to length of stay in this homogeneous group of patients. Because the numbers are small and the patients as a group did well, no statement can be made regarding specific complications or clinically apparent organ dysfunction and outcome. Further study of a larger group of potentially sicker patients may be necessary to answer some of the questions posed by this information.

Although the neutrophil count and the production of leukotrienes after cardiopulmonary bypass is correlated with outcome, the data are consistent with the hypothesis that neutrophil activation occurs during cardiopulmonary bypass and that leukotrienes may have a significant role in the postoperative outcome. The exact mechanism behind this observation can only be speculated and is currently under investigation. Similar data collected in consecutive patients undergoing repair of abdominal aortic aneurysm showed a close correlation between aortic crossclamp time and leukotriene generation by the patients' neutrophils and clinical outcome. ${ }^{28}$

The precise mechanism resulting in activation of the neutrophils is unknown but under investigation. These data suggest that altering neutrophil count or neutrophil leukotriene generation may alter the postoperative outcome in these patients. This theory too is under investigation.

\section{REFER E N CES}

1. Butler J, Rocker GM, Westaby S. Inflammatory response to cardiopulmonary bypass. Ann Thorac Surg 1993;55: 552-9.

2. Ts'ao C, Lin C-Y, Glagov S, Replogle RL. Disseminated leukocyte injury during open-heart surgery. Arch Pathol 1973;95:357-65.

3. Colman RW. Platelet and neutrophil activation in cardiopulmonary bypass. Ann Thorac Surg 1990;49:32-4.

4. Wachtfogel YT, Kucich U, Greenplate J, et al. Human neutrophil degranulation during extracorporeal circulation. Blood 1987;69:324-30. 
5. Faymonville ME, Pincemail J, Duchateau J, et al. Myeloperoxidase and elastase as markers of leukocyte activation during cardiopulmonary bypass in humans. $\mathbf{J}$ THORAC Cardiovasc Surg 1991;102:309-17.

6. Tennenberg SD, Clardy CW, Bailey WW, Solomkin JS. Complement activation and lung permeability during cardiopulmonary bypass. Ann Thorac Surg 1990;50:597-601

7. Riegel W, Spillner G, Schlosser V, Hörl WH. Plasma levels of main granulocyte components during cardiopulmonary bypass. J THORAC CARDIOvASC SuRG 1988;95:10149.

8. Stahl RF, Fisher CA, Kucich U, et al. Effects of stimulated extracorporeal circulation on human leukocyte elastase release, superoxide generation, and procoagulant activity. $J$ Thorac Cardiovasc Surg 1991;101:230-9.

9. Antonsen S, Brandslund I, Clemensen S, S $\phi$ feldt S, Madsen T, Alstrup P. Neutrophil lysosomal enzyme release and complement activation during cardiopulmonary bypass. Scand J Cardiovasc Surg 1987;21:47-52.

10. Elgebaly SA, Houser S, Elkerm AF, Doyle K, Purlman K, Allam ME. Evidence of cardiac inflammation after open heart surgery. Surg Forum 1991;42:274-8.

11. Haddix TL, Montgomery KF, Pohlman TH. Verrier ED. Reversible inhibition of endothelial leukocyte adhesion molecule-1 (ELAM-1) expression in hypothermic endothelial cells. Surg Forum 1991;42:213-6.

12. Datta $\mathrm{S}$, Engelman RM, Low $\mathrm{H}$, et al. Interleukin-1 expression and its regulation of oxygen-free radical production in patients undergoing cardiopulmonary bypass. Surg Forum 1991;42:280-2.

13. Kirklin JK, Westaby S, Blackstone EH, Kirklin JW, Chenoweth DE, Pacifico AD. Complement and the damaging effects of cardiopulmonary bypass. J THORAC CARDIOVASC SURG 1983;86:845-57.

14. Hammerschmidt DE, Stroncek DF, Bowers TK, et al. Complement activation and neutropenia occurring during cardiopulmonary bypass. J THORAC CARDIOVASC SURG 1981;81:370-7.

15. Chenoweth DE, Cooper SW, Hugli TE, Stewart RW, Blackstone EH, Kirklin JW. Complement activation during cardiopulmonary bypass. N Engl J Med 1981;304:497503.

16. Lee CC, Appleyard RF, Laurence RG, Byrne JG, Cohn LH. Inhibition of leukotrienes improves global function, myocardial salvage, and reduces ventricular irritability after acute regional ischemia and surgical reperfusion. Surg Forum 1991;42:278-80.

17. Jansen NJG, van Oeveren W, Broek Lvd, et al. Inhibition by dexamethasone of the reperfusion phenomena in cardiopulmonary bypass. J THORAC CARDIOvASC SURG 1991; 102:515-25.

18. Tennenberg SD, Bailey WW, Cotta LA, Brodt JK, Solomkin JS. The effects of methylprednisolone on complement-mediated neutrophil activation during cardiopulmonary bypass. Surgery 1986;100:134-41.

19. Boyum A. Isolation of mononuclear cells and granulocytes from human blood: isolation of mononuclear cells by one centrifugation and of granulocytes by combination centrifugation and sedimentation at 1 g. J Lab Clin Invest 1968; 97:77-94

20. Borgeat P, Samuelsson B. Arachidonic acid metabolism in polymorphonuclear leukocytes: effect of ionophore A23187. Proc Natl Acad Sci U S A 1979;76:2148-50.

21. Metcalf JA, Gallin JI, Nauseef WM, Root RK. Laboratory manual of neutrophil function. New York: Raven, 1986:96-100.

22. Davis JM, Yurt RW, Barie PS, et al. Leukotriene $\mathrm{B}_{4}$ generation in patients with established pulmonary failure. Arch Surg 1989;124:1451-5.

23. Samuelsson B. Leukotrienes: mediators of immediate hypersensitivity reactions and inflammation. Science 1983; 220:568-75.

24. Gadaleta D, Davis JM. Pulmonary failure and the production of leukotrienes. J Am Col Surg [In press].

25. Davis JM, Meyer JD, Barie PS, et al. Elevated production of neutrophil leukotriene $\mathrm{B}_{4}$ precedes pulmonary failure in critically ill surgical patients. Surg Gynecol Obstet 1990 170:495-500.

26. Rivkind AI, Siegel JH, Guadalupi P, Littleton M. Sequential patterns of eicosanoid, platelet, and neutrophil interactions in the evolution of the fulminant post-traumatic adult respiratory distress syndrome. Ann Surg 1989;210:355-73.

27. Root RK, Metcalf J, Oshino N, Chance B. $\mathrm{H}_{2} \mathrm{O}_{2}$ release from human granulocytes during phagocytosis. I. Documentation, quantitation and some regulating factors. J Clin Invest 1975;53:1207-15.

28. Gadaleta D, Fantint G, Silane MF, Davis JM. Neutrophil leukotriene generation and pulmonary dysfunction following abdominal aortic aneurysm repair surgery. Surgery [In press]. 